\title{
Neuropsychological Tests for Patients with Marchiafava-Bignami Disease: A Case Report
}

\author{
HyunChul Youn, Soyoung Irene Lee, Shin-Gyeom Kim, Jeewon Lee, and Han-yong Jung ${ }^{\bowtie}$ \\ Department of Psychiatry, Soonchunhyang University Bucheon Hospital, Bucheon, Republic of Korea
}

To the Editor,

Here we report a case of a male patient with MarchiafavaBignami disease (MBD). This report focuses on the clinical presentation and neuropsychiatric symptoms of MBD. The study was approved by the Institutional Review Board (IRB) of Soonchunhyang University Bucheon Hospital (2020-07-023).

A 37-year-old male patient visited the outpatient clinic and presented with a 9-month history of lack of energy. He is a high-school graduate and an office worker living with his wife and two children. He had no underlying disease, but drank 4-6 bottles of soju (about 28-42 alcohol units) every day for the past five years. During the interview, he spoke very little. According to his wife, he has been slow to do everything for the past six months, and was unable to perform his job. He could not even do simple things at home until his wife ordered him. Even so, the patient's performance was very lethargic. For example, he took several hours to get ready to go out. His wife reported that the lack of energy, apathy, and distraction were the main issues.

Laboratory screening was normal. His neurological examination revealed no neurological deficit. Magnetic resonance imaging (MRI) of the brain demonstrated a bilaterally symmetrical T2/FLAIR high-signal intensity lesion involving corpus callsosum genu, body, bilateral frontal white matter, internal capsule, and corticospinal tracts (Figure 1). According to his brain MRI report, the patient was suspected to have MBD. During the patient's first visit, some questionnaires were administered and the respective scores obtained were: Generalized Anxiety Disorder-7, Patient Health Questionnaire-9, and Pittsburgh Sleep Quality Index-1, 8, and 1. The scores revealed

Received: September 2, 2020 Revised: October 23, 2020

Accepted: November 1, 2020

$\triangle$ Correspondence: Han-yong Jung, MD, PhD

Department of Psychiatry, Soonchunhyang University Bucheon Hospital, 170 Jomaru-ro, Bucheon 14584, Republic of Korea

Tel: +82-32-621-5063, Fax: +82-32-621-6950, E-mail: hanyjung@schmc.ac.kr (c) This is an Open Access article distributed under the terms of the Creative Commons Attribution Non-Commercial License (https://creativecommons.org/licenses/bync/4.0) which permits unrestricted non-commercial use, distribution, and reproduction in any medium, provided the original work is properly cited. mild depression, but no evidence of clinically significant depression was detected during the interview. Initial scores of Mini-Mental Status Examination (MMSE) and Global Deterioration Scale (GDS) were 27 (time orientation -1, recall -2) and 3, respectively. The patient also underwent a battery of neuropsychological tests. Overall intellectual ability of the patient was borderline level. The patient exhibited very low levels of memory and frontal-executive functions, and decreased social function and activities of daily life. The performance in emotion-related tests was generally non-specific. Detailed results are presented in Table 1.

We initially administered $50 \mathrm{mg}$ of IV thiamine and gradually increased to $600 \mathrm{mg}$. After 15 days of treatment, the patient's wife reported that his memory and apathy symptom were slightly improved. He often spoke something and laughed while watching TV unlike before. However, there was a wide fluctuation in his symptoms, and his slowness was not improved. The MMSE and GDS tests were also checked again. The total scores of these scales were the same as the initial values, but the subscores of MMSE changed (time orientation -1, recall $-2 \rightarrow$ time orientation -1 , attention and concentration -1 , recall -1$)$.

MBD is a rare sequelae of chronic alcoholism, and can result in progressive demyelination and necrosis of the corpus callosum. ${ }^{1}$ A brain MRI may be necessary for MBD diagnosis. ${ }^{2,3}$ The clinical presentation of this disease includes various non-specific symptoms and signs, such as decreased consciousness, psychotic symptoms, depression, apathy, aggression, seizures, hemiparesis, ataxia, apraxia, confusion, dysarthria, behavioral abnormalities, memory deficits, gait disorders, coma, and death. ${ }^{4}$ Until now, there have been few guidelines for management of MBD. Several case reports of MBD have demonstrated the effectiveness of treatment with thiamine, corticosteroid, or amantadine. ${ }^{1,4,5}$ However, the prognosis of this condition is worse: as of 2004, among approximately 250 reported patients, only 20 experienced positive outcomes. ${ }^{4}$

The present case presents a 37 -year-old male patient with MBD. The chief complaints were lack of energy, apathy, and 
distraction, although the general medical condition was relatively fine. The initial MMSE and GDS scores were relatively less severe than our clinical impression. However, the battery of neuropsychological tests revealed the patient's problem such as cognitive impairment in further detail. Based on our case results, clinicians may consider adopting a detailed neuropsy-
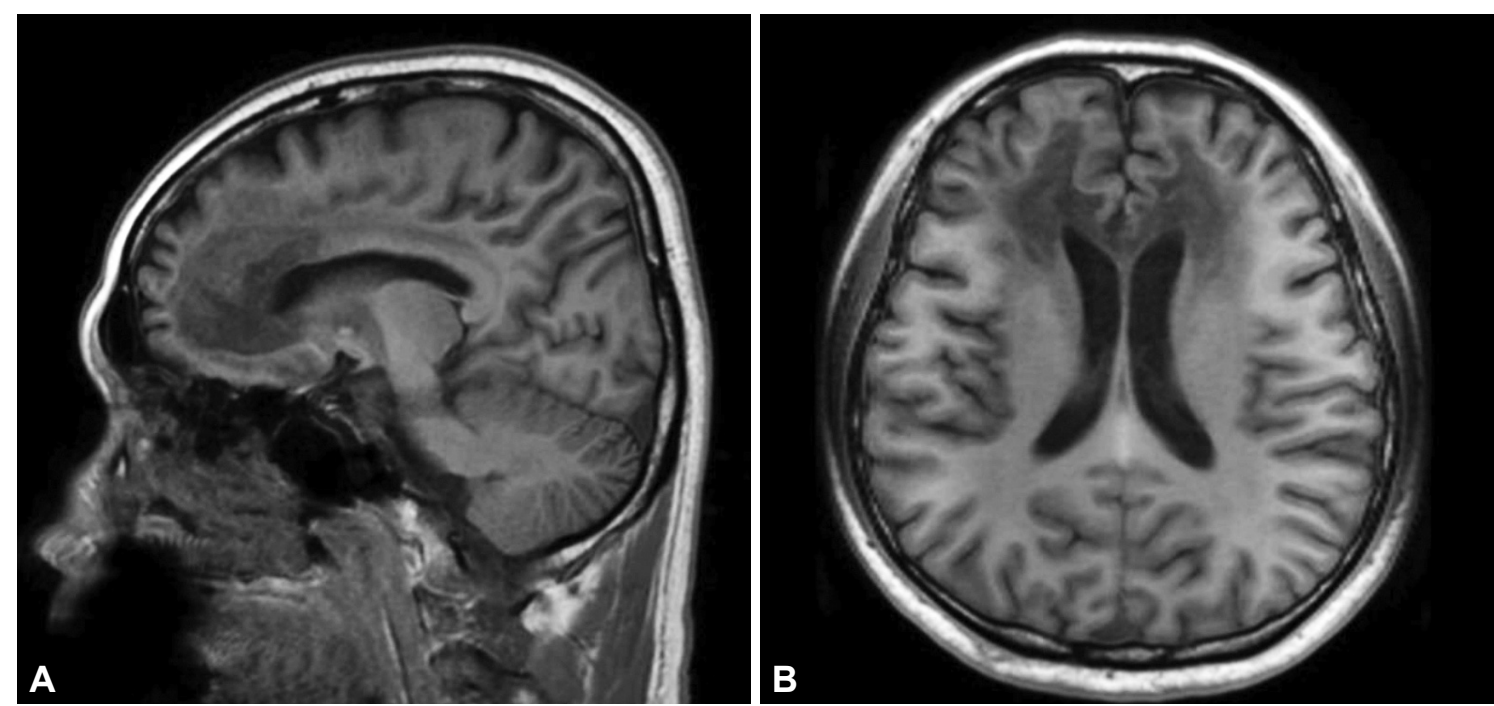

Figure 1. Brain magnetic resonance imaging of the patient. A: Sagittal view of T1-weighted brain image. B: Axial view of T1-weighted brain image. The summary of MRI findings: Bilaterally symmetrical T2/FLAIR high-signal intensity lesion involving corpus callsosum genu, body, bilateral frontal white matter, internal capsule, and corticospinal tracts, Marchiafava-Bignami disease involvement.

Table 1. The detailed scores of neuropsychological battery

\begin{tabular}{cc}
\hline Tests & Results \\
\hline
\end{tabular}

Test of visual-motor integration

Korean Wechsler Adult Intelligence Scale-IV

Rey-Kim memory scale-II

Kims frontal-executive function scale-II

Social maturity scale

Korean-symptom check list 95
18, borderline level

FSIQ $=75$, 5\%ile, borderline level

$\mathrm{VCI}=77,7 \%$ ile, borderline level

PRI $=80,9 \%$ ile, low average level

$\mathrm{WMI}=90,25 \%$ ile, average level

PSI $=84,14 \%$ ile, low average level

$\mathrm{MQ}=52,0.1 \%$ ile, very low level

$\mathrm{VMI}=52,0.1 \%$ ile, very low level

$\mathrm{FMI}=68,2 \%$ ile, very low level

IRCI $=56,0.2 \%$ ile, very low level

DRCI $=54,0.1 \%$ ile, very low level

DRGI $=65,1 \%$ ile, very low level

$\mathrm{EFQ}=68,2 \%$ ile, very low level

Social quotient $=77$, social age $=13.80$

DEP: 41, ANX: 44, PHOB: 51, PAN: 59, AGO: 44, O-C: 32, OBS: 37, OPD: 31, PTSD: 55 , AGG: 45, SOM: 41, MAN: 41, PAR: 43, SCH: 52, SUC: 47, ADD: 44, SI-P: 41, ST-V: 40, IN-S: 40, RG-P: 41

Minnesota multiphasic personality inventory-II $\quad$ Hs: 48, D: 43, Hy: 50, Pd: 46, Mf: 53, Pa: 41, Pt: 50, Sc: 47, Ma: 47, Si: 45

FSIQ: full scale intelligence quotient, VCI: verbal comprehension index, PRI: perceptual reasoning index, WMI: working memory index, PSI: processing speed index, MQ: memory quotient, VMI: verbal memory index, FMI: figural memory index, IRCI: immediate recall index, DRCI: delayed recall index, DRGI: delayed recognition index, EFQ: executive function quotient, DEP: depression, ANX: anxiety, PHOB: phobic anxiety, PAN: panic, AGO: agoraphobia, O-C: obsessive-compulsive, OBS: obsessive symptoms, OPD: obsessive personality, PTSD: posttraumatic stress disorder, AGG: aggression, SOM: somatic, MAN: mania, PAR: paranoia, SCH: schizophrenia, SUC: suicidal, ADD: addiction, SI-P: sleep problems, ST-V: stress vulnerability, IN-S: interpersonal sensitivity, RG-P: regulation problems, Hs: hypochondriasis, D: depression, Hy: hysteria, Pd: psychopathic deviate, Mf: masculinity-femininity, Pa: paranoia, Pt: psychasthenia, Sc: schizophrenia, Ma: hypomania, Si: social introversion 
chological battery to better understand the clinical manifestations of patients with MBD. Unlike other case report, ${ }^{1}$ the effects of parenteral thiamine therapy in our case were inadequately reflected by the MMSE scores, although the caregiver reported a slight improvement of symptoms. We speculate that it may be associated with relatively high level of initial MMSE score of our patient.

MBD was first described in 1903 by Italian pathologists, ${ }^{6}$ but few studies have been reported since then except a few case reports because of low prevalence. Accordingly, MBD is not clearly understood and additional reports are still needed. In our case report, we introduced male MBD patients with cognitive impairment based on a battery of neuropsychological tests and relatively fine general condition. Clinicians may have the potential to meet MBD patients at any time because of the large population of chronic alcoholic patients worldwide. We believe that our report may help clinicians assess and treat patients with MBD.

\section{Acknowledgments}

This study was supported by the Soonchunhyang Research Fund.

\section{Conflicts of Interest}

The authors have no potential conflicts of interest to disclose.

\section{Author Contributions}

Conceptualization: Han-yong Jung. Data curation: HyunChul Youn.
Formal analysis: HyunChul Youn. Funding acquisition: Han-yong Jung. Investigation: HyunChul Youn. Methodology: HyunChul Youn, Jeewon Lee, Soyoung Irene Lee. Project administration: Shin-Gyeom Kim, Han-yong Jung. Supervision: Han-yong Jung. Validation: Shin-Gyeom Kim, Jeewon Lee, Soyoung Irene Lee. Visualization: HyunChul Youn. Writing_original draft: HyunChul Youn. Writing_review \& editing: all authors.

\section{ORCID iDs}

HyunChul Youn https://orcid.org/0000-0002-6557-5628

Soyoung Irene Lee https://orcid.org/0000-0003-2473-2954

Shin-Gyeom Kim https://orcid.org/0000-0001-8196-655X

Jeewon Lee https://orcid.org/0000-0001-5930-1834

Han-yong Jung https://orcid.org/0000-0003-0089-0368

\section{REFERENCES}

1. Nemlekar SS, Mehta RY, Dave KR, Shah ND. Marchiafava: Bignami disease treated with parenteral thiamine. Indian J Psychol Med 2016; 38:147-149.

2. Arbelaez A, Pajon A, Castillo M. Acute Marchiafava-Bignami disease: MR findings in two patients. AJNR Am J Neuroradiol 2003;24:19551957.

3. Heinrich A, Runge U, Khaw AV. Clinicoradiologic subtypes of Marchiafava-Bignami disease. J Neurol 2004;251:1050-1059.

4. Carrilho PE, Santos MB, Piasecki L, Jorge AC. Marchiafava-Bignami disease: a rare entity with a poor outcome. Rev Bras Ter Intensiva 2013; 25:68-72.

5. Kikkawa Y, Takaya Y, Niwa N. A case of Marchiafava-Bignami disease that responded to high-dose intravenous corticosteroid administration. Rinsho Shinkeigaku 2000;40:1122-1125.

6. Marchiafava E. Marchiafava-Bignami disease with only slowly progressive cognitive impairment. Riv Patol Nerv Ment 1903;8:544-549. 